\title{
Maria Skłodowska-Curie - the first lady of nuclear physics
}

\author{
Tomasz Pospieszny \\ Laboratory of Microbiocides Chemistry, Faculty of Chemistry, Adam Mickiewicz University in Poznan, Poland
}

Radium was not to enrich anyone. Radium is an element. It belongs to all people

\section{Maria Skłodowska-Curie}

The history of nuclear chemistry and physics as well as brachytherapy began on February 1896 in Paris. After the discovery of X-rays in 1895 by the German physicist Wilhelm Conrad Röntgen (1845-1923), the French physicist Antoine Henri Becquerel (1852-1908) fortuitously discovered that minerals of uranium spontaneously emitted rays very similar to $\mathrm{X}$-rays. It was a milestone in the history of nuclear physics and chemistry as well as modern medicine [1]. However, the development of brachytherapy is directly related to the genius and systematic work of Maria Skłodowska-Curie (1867-1934) and her husband Pierre Curie (1859-1906) [2]. Subsequently, when Irène (1897-1956) and Frédéric Joliot-Curie (1900-1958) discov-



Photo 1. Wilhelm Conrad Röntgen, b.d., Wellcome Collection (public domain) ered artificial radioactivity in 1934, they opened a new path to brachytherapy $[3,4]$.

On December $28^{\text {th }} 1895$, Röntgen (Photo 1) published the results of the research in Ueber eine neue Art von Strahlen (On a new type of ray) [5]. It was the beginning of a scientific revolution. Very quickly the whole world of science learned about the unusual discovery of a German. This discovery was so important that Wilhelm Conrad Röntgen became the first Nobel Prize winner in physics in 1901. The justification states that he received the prize "in recognition of the extraordinary services he has rendered by the discovery of the remarkable rays subsequently named after him".

In January 1896 at the session of the Academy of Sciences in Paris, Henri Poincaré (1854-1912) suggested that X-rays may be similar to fluorescence. Fascinated by this information, Becquerel (Photo 2) began a series of stud-

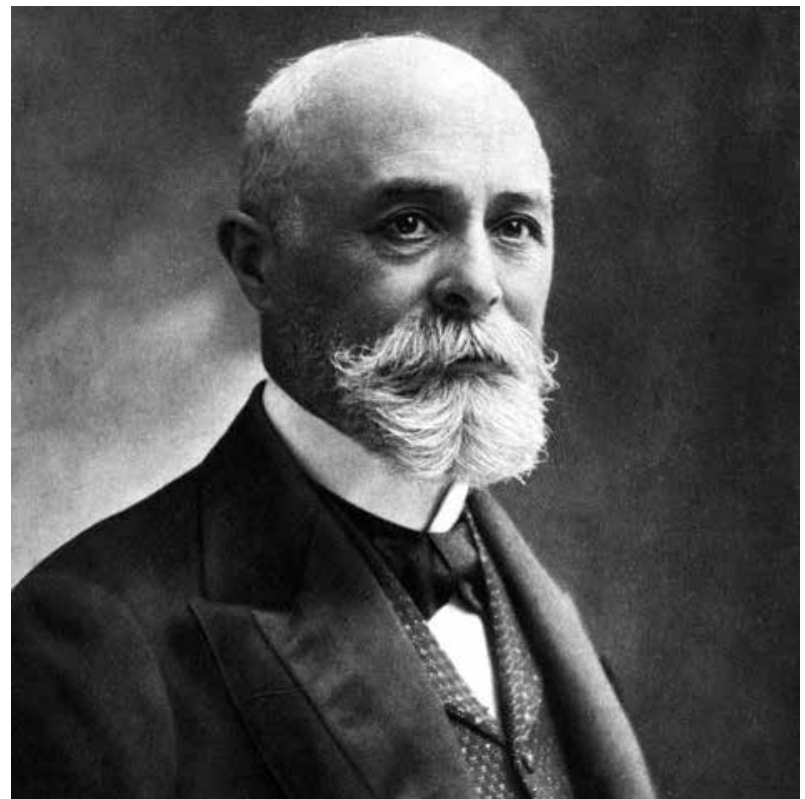

Photo 2. Antoine-Henri Becquerel, 1908, photo: P. Nadar, Smithsonian Institution Libraries (public domain)
Address for correspondence: Tomasz Pospieszny, Laboratory of Microbiocides Chemistry, Faculty of Chemistry, Adam Mickiewicz University in Poznań, 8 Uniwersytetu Poznańskiego St., 61-614 Poznań, Poland, ๙ e-mail: tposp@amu.edu.pl
Received: 05.12.2019 Accepted: 06.12 .2019 Published: 23.12.2019 
ies on uranium salts. He exposed them to sunlight and then he applied salts to photographic plates that became black. At the end of February 1896, it was cloudy and rainy in Paris. Becquerel could not expose the uranium salts in solar radiation. He placed a photographic plate and unexposed salt in a drawer. After a few days he decided to develop a photographic plate. To his surprise, it was blackened. Uranium salts emit radiation without solar radiation. Becquerel identified natural radioactivity in his photographic plate in contact with uranium crystals. He himself published seven papers on radioactivity in 1896, and two in 1897 and none the year after. After the discovery of polonium and radium in 1898 by the Curies, Becquerel wrote only four papers in 1899. Becquerel's observations showed that uranium and its compounds in crystallized form dissolved or molten spontaneously emitted radiation. He also noticed that this radiation blacked the photographic plates, ionized the air, penetrated through nontransparent bodies, and it was similar to visible light, i.e. it was reflected, refracted, and polarized; therefore, uranium radiation was similar to electromagnetic radiation [1]. As it turned out, his last observation was false and resulted from misinterpretation of the experiments. It was the great discovery which Maria Skłodowska-Curie would later name radioactivity.

At the end of 1897 Maria Skłodowska-Curie (Photo 3) chose as the subject of her doctoral thesis the investigation of uranium rays. Because Becquerel investigation only two properties of uranium rays - the effect on photographic plates and ionization - Maria focused on a second measurable property. She first repeated the Becquerel experiments, and then instead of the photographic plates used by him she used a very sensitive electrometer with piezoelectric quartz. Thanks to systematic and very exact measurements Maria Skłodowska-Curie stated that radiation of uranium depends on the amount of uranium and is proportional to it. It was a milestone in the study of radioactivity. Maria was the first to state that radiation is the atomic property of uranium! Although similar studies were carried out in Naples by Emilio Villari (1836-1904), he probably did not even think of similar conclusions [6]. Then, Maria collected many elements in the free state or as compounds and rapidly came to the conclusion that, besides uranium, also thorium emits radiation. She made this discovery regardless of the German physics Gerhard Carl Schmidt (1865-1949). Of all the elements Madame Curie tested, only two - uranium and thorium - gave off invisible ionizing rays, and Maria Skłodowska-Curie named the new phenomenon as "radio-activity" in 1898. These rays became generally known as "Becquerel rays", a term first used by Maria Skłodowska-Curie in the same year. At the same time, she proved that the emission of radiation by thorium is quantitatively different from the emission of uranium. No one else carried out such research. Her research results became the basis for her doctoral dissertation in 1903 [7]. It is worth noting that Pierre Curie (Photo 4) also participated in these works, and (as he thought) temporarily left his studies on crystals. Another important observation of Maria Skłodowska-Curie was the fact that the emission of radiation of some minerals containing uranium: pitchblende, chalcolite or autunite are much stronger than it would appear from the content of uranium in their composition. Because Maria knew the chemical composition of chalcolite, she found that only uranium was a radioactive element in this mineral. She put forward a bold hypothesis that this mineral must contain a new, unknown chemical element. On July $28^{\text {th }} 1898$ the Curies wrote: "Certain minerals containing uranium and thorium (pitchblende, chalcolite, uranite) are very active from the point of view of the emission of Becquerel rays. In a preceding communication, one of us showed that their activity was even greater than that of

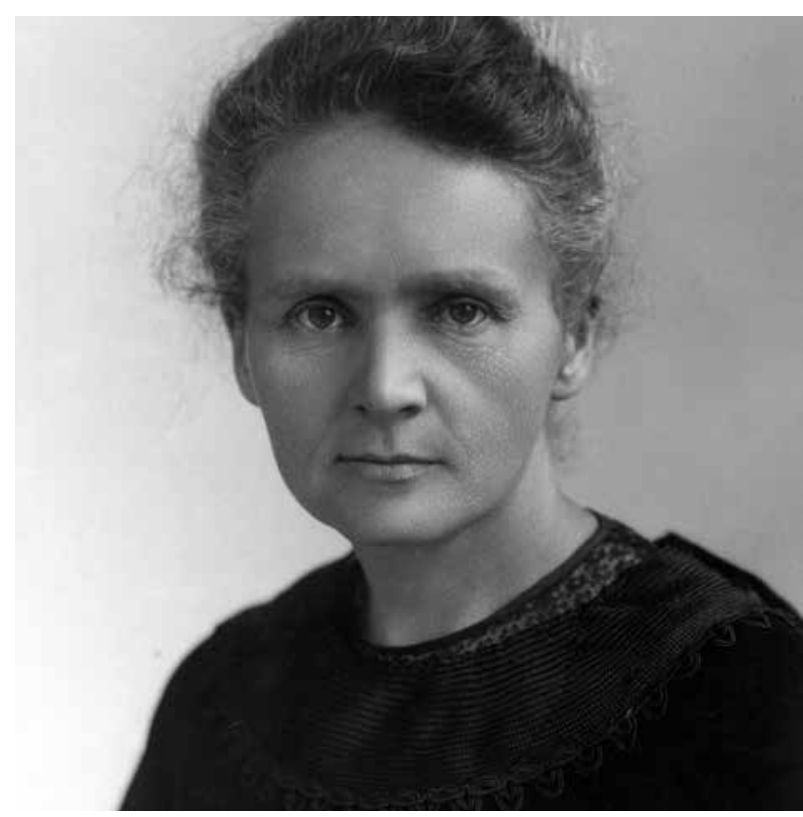

Photo 3. Marie Skłodowska-Curie, Birmingham, 1913, Musée Curie (coll. ACJC)

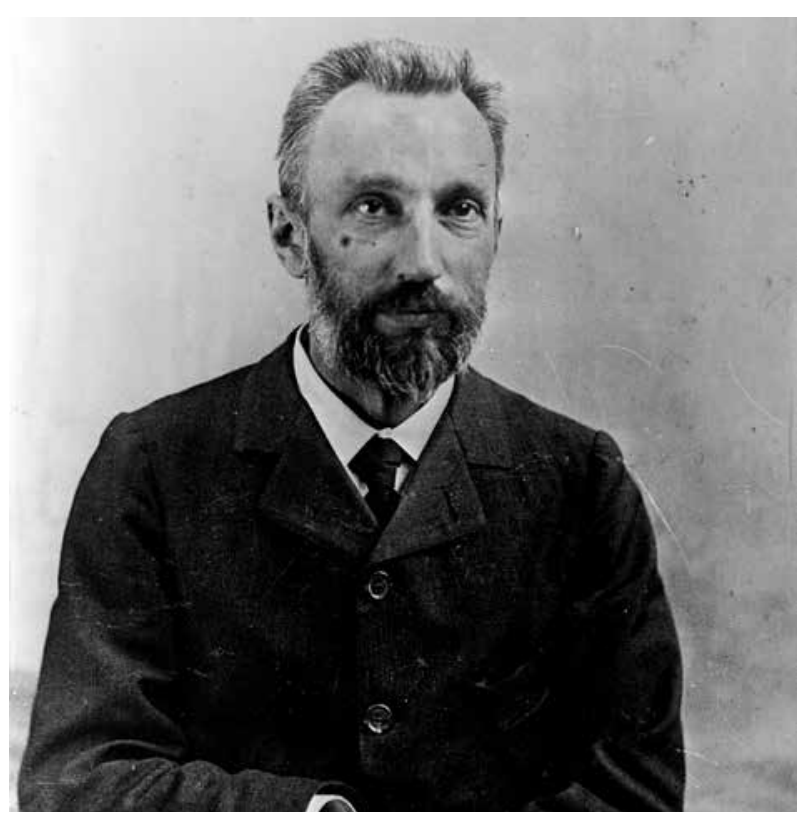

Photo 4. Pierre Curie, 1905, Musée Curie (coll. ACJC) 
uranium and thorium, and stated the opinion that this effect was due to some other very active substance contained in a small quantity in these minerals" [8]. The first step to confirm it was the chemical synthesis of chalcolite. Maria had proved that synthetic chalcolite emits weaker radiation, i.e. what would be expected from the uranium content of this mineral (Photo 5). It was indisputable experimental evidence for the existence of a new chemical element [9]. Together, the Curies using their radioactive indicator method determined the radiation of the new element. It radiated four hundred times stronger than uranium [2]. In the Proceedings of the Academy for July 1898 they wrote: "We believe the substance we have extracted from pitchblende contains a metal not yet observed, related to bismuth by its analytical properties. If the existence of this new metal is confirmed we propose to call it polonium, from the name of the original country of one of us" [8].

The Curies did not have to wait too long for another success. In November they conducted a series of experiments, thanks to which they received a very radioactive product. With the participation of Gustav Bémont (18571932), they managed to obtain a sample containing barium with radioactivity nine hundred times greater than uranium! On December $26^{\text {th }}, 1898$, together with assistant Bémont, they announced that they had discovered a second chemical element - radium. They wrote: "The various reasons we have just enumerated lead us to believe that the new radioactive substance contains a new element to which we propose to give the name of RADIUM. The new radioactive substance certainly contains a very strong proportion of barium; in spite of that its radioactivity is considerable. The radioactivity of radium therefore must be enormous" [8]. Polonium and radium were observed by the Curies due to high radioactivity. Now scientists needed additional evidence to confirm that both elements existed. Eugène Demarçay (1852-1904), a specialist in the field of emission spectroscopy, took spectra of newly discovered elements. Demarçay heated polonium and radium-containing substances to a gaseous state in a torch flame, and then analyzed the spectra that arose as a result of the light they split. Curies had proof of the existence of radium in the form of an emission spectrum that showed a weak but distinct purple line at $381.48 \mathrm{~nm}$ corresponding to this element [2]. Unfortunately, the concentration of polonium in the sample was too weak to observe the emission line. The three radioactive elements uranium, thorium and radium belong to the long-lived elements, so that scientists hardly observed any decrease in their radioactivity. In turn, polonium is one of the short-lived elements for which radioactive activity decreases with time. Maria Skłodowska-Curie hypothesized that the radioactive activity is constant for a given element. So there was doubt whether polonium was not a bismuth, whose activity was raised by the radium. In addition, the presence of only bismuth lines in the emission spectrum was in favor of this hypothesis. On the other hand, Maria concluded that the amount of polonium in the sample could be so small that its line was not noticed. Building on this bold idea, Maria Skłodowska-Curie, together with Pierre Curie, founded the field of radiochemistry $[10,11,12]$.

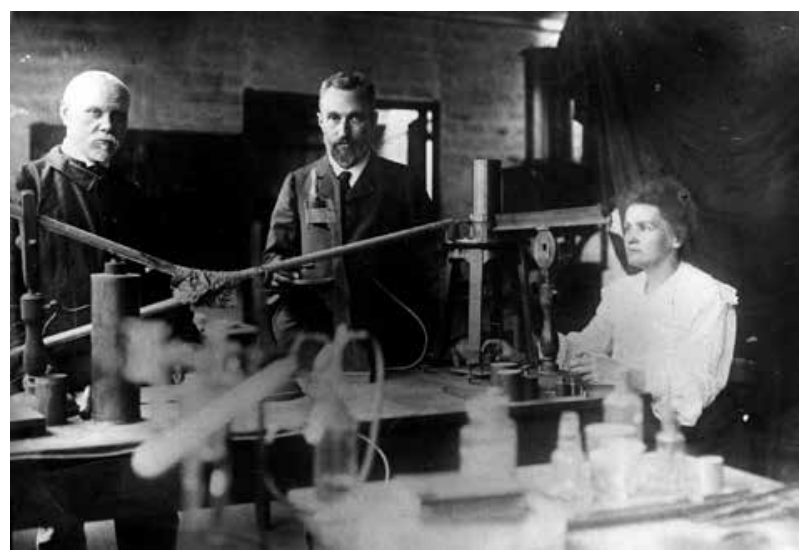

Photo 5. Pierre and Marie Curie with Monsieur Petit (lab assistant) in their laboratory, the "hangar of discovery", at the School of Physical and Industrial Chemistry of the city of Paris, about 1898, Musée Curie (coll. ACJC)

It is noteworthy that one of the greatest discoveries in human history was made in very primitive conditions. The Curies" "laboratory" was an old shed (a former dissecting room) (Photos 6-8). The German chemist Wilhelm Ostwald (1853-1932) visited the Curies to see how they worked. He later wrote: "At my earnest request, I was shown the laboratory where radium had been discovered shortly before... It was a cross between a stable and a potato shed, and if I had not seen the worktable and items of chemical apparatus, I would have thought that I had been played a practical joke" [2]. In her autobiography Maria wrote: "Yet it was in this miserable old shed that we passed the best and happiest years of our life, devoting our entire days to our work. Often I had to prepare our lunch in the shed, so as not to interrupt some particularly important operation. Sometimes I had to spend a whole day mixing a boiling mass with a heavy iron rod nearly as large as myself. I would be broken with fatigue at the day's end. On other days, however, the work would be a most minute and delicate fractional crystallization, in the effort to concentrate the radium. I was then annoyed

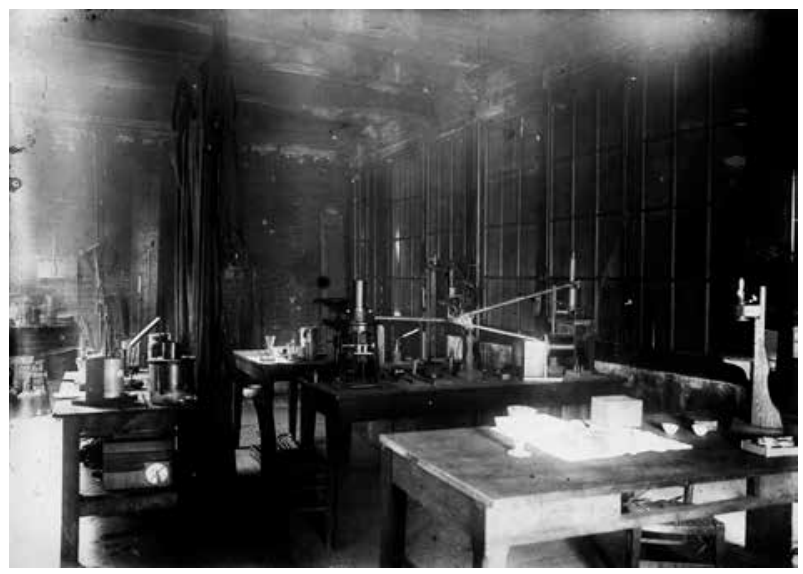

Photo 6. Interior of the "shed" laboratory of Pierre and Marie Curie, at the School of Physics and Industrial Chemistry of the city of Paris, about 1898, Musée Curie (coll. ACJC) 

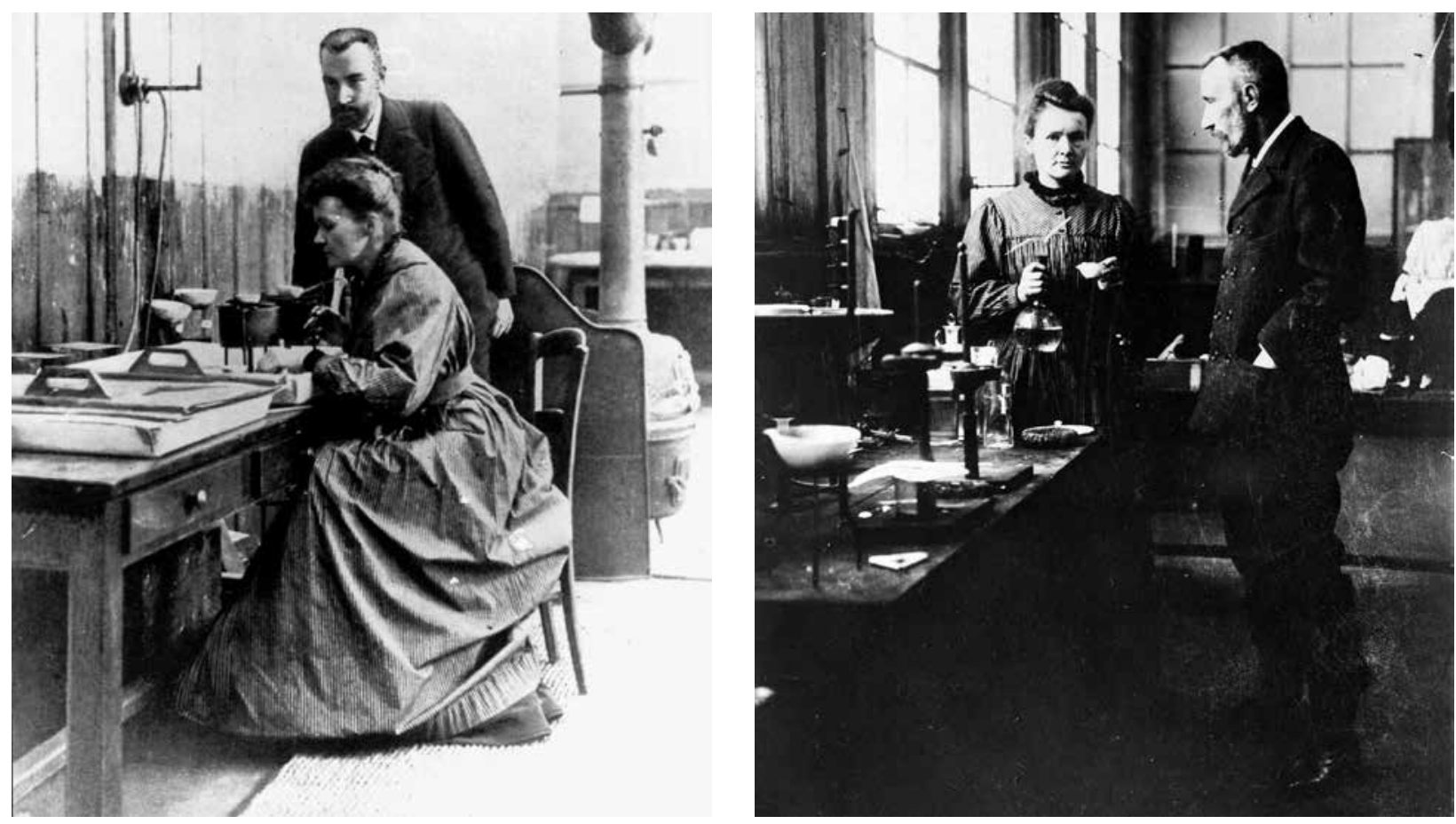

Photos 7 and 8. Pierre and Marie Curie in the laboratory, called the "hangar of the discovery", at the School of Physics and Industrial Chemistry, around December 1903, Musée Curie (coll. ACJC)

by the floating dust of iron and coal from which I could not protect my precious products. But I shall never be able to express the joy of the untroubled quietness of this

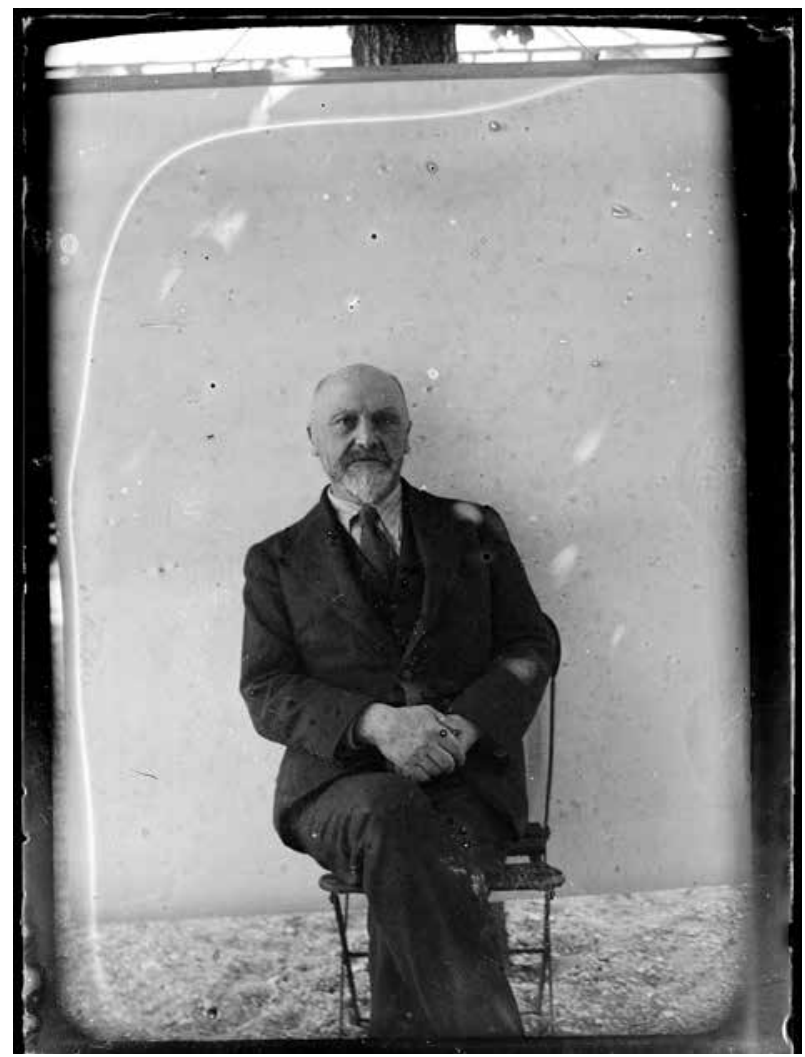

Photo 9. André Debierne around 1940, Musée Curie (coll. ACJC) atmosphere of research and excitement of actual progress with the confident hope of still better results. The feeling of discouragement that sometimes came after some unsuccessful toil did not last long and gave way to renewed activity. We had happy moments devoted to a quiet discussion of our work, walking around our shed. One of our joys was to go into our workroom at night; we then perceived on all sides the feebly luminous silhouettes of the bottles or capsules containing our products. It was really a lovely sight and one always new to us. The glowing tubes looked like faint, fairy lights" [13].

The natural consequence of Maria and Pierre Curie's discoveries was to enrich Mendeleev's periodic table of elements with another element. In 1899 the Curies' friend Andre-Louis Debierne (1874-1949) (Photo 9), had found another new active substance in pitchblende. He named it actinium, probably from actinic, the era's term for radiation that darkened a photographic plate. Debierne thought actinium resembled thorium chemically. He wondered whether thorium's radioactivity was really caused by traces of actinium.

Research on new radioactive elements was extremely interesting, intriguing, innovative and gave a lot of hope for the application of their properties in medicine. Studies of Pierre Curie were described by Maria in her biography. She wrote: "Finally, I cannot pass in silence, because of their various repercussions, the experiments connected with the physiological effects of radium. In order to test the results that had just been announced by F. Giesel, Pierre Curie voluntarily exposed his arm to the action of radium for several hours. This resulted in a lesion resembling a burn, which developed progressively and required several months to heal. Henri Becquerel had by 
accident a similar burn as a result of carrying in his vest pocket a glass tube containing radium salt. He came to tell us of this evil effect of radium, exclaiming in a manner at once delighted and annoyed: "I love it, but I owe it a grudge!". Since he realized the interest in these physiological effects of radium, Pierre Curie undertook, in collaboration with physicians, the investigations to which I have just referred, submitting animals to the action of radium emanation. These studies formed the point of departure in radium therapy. The first attempts at treatment with radium were made with products loaned by Pierre Curie, and had as their object the cure of lupus and other skin lesions. Thus radium therapy, an important branch of medicine, and frequently designated as Curietherapie, was born in France, and was developed first through the investigations of French physicians (Danlos, Oudin, Wickham, Dominici, Cheron, Degrais, and others)" [13]. Maria and Pierre Curie started a new type of chemistry radiation chemistry - and a new therapy, which would later be called curietherapy [14]. Curie also noted that inactive substances near radioactive bodies become briefly radioactive. This phenomenon is called radioactivity excitation.

The whole world was crazy about radium and radioactivity. Maria Skłodowska-Curie was hailed as the Radium Madonna. Curie received many prestigious awards for their work: Plante, Lacaze, Gegner, Osiris, Davy's Medal. This discovery was so important to science as well as medicine that Becquerel and Maria and Pierre Curie became the Nobel Prize winners in physics in 1903. The justification states that Becquerel received a prize "in recognition of the extraordinary services he has rendered by his discovery of spontaneous radioactivity", and the Curies "in recognition of the extraordinary services they have rendered by their joint research on the radiation phenomena discovered by Professor Henri Becquerel" $[15,16,17]$.

After Maria and Pierre Curie first discovered the radioactive elements polonium and radium, Maria continued to investigate their properties (Pierre Curie died in a traffic accident in 1906). In 1910 she successfully obtained radium as a pure metal. It was evidence that radium is a chemical element. Maria Skłodowska-Curie also studied and described the properties of the radioactive elements and their compounds. For this work, she received the second Nobel Prize in 1911 in chemistry. The justification states that she received the prize "in recognition of her services to the advancement of chemistry by the discovery of the elements radium and polonium, by the isolation of radium and the study of the nature and compounds of this remarkable element".

In my opinion, besides a great experimenter, Maria Skłodowska-Curie was a great visionary of science, who was years ahead of her time. On $14^{\text {th }}$ June 1900 at the Sorbonne Maria Curie developed her hypothesis of possibility of the transformation of atoms. She suggested: "The material radioactive theory fully considers phenomena noted so far. However, if we are to accept this theory, we will have to concede that radioactive matter is not a normal chemical state. In this case, the atom is not unchanging and indivisible, since its particles are radiat- ed out. Radioactive matter is subject to chemical transformation, and that very change is the source of energy in radiation; but it is not a usual chemical transformation, for here the atom itself is subject to change. It is apparent after all that if radioactivity is a result of transformation of matter, then the atom must transform, as radioactivity is an atomic phenomenon" [1].

\section{Acknowledgements}

The author would like to thank the Musée Curie in Paris for sharing the photographs.

\section{Disclosure}

The author reports no conflict of interest.

\section{References}

1. Hurwic J. Maria Skłodowska-Curie and radioactivity. Galant Edition, Warsaw 2011.

2. Pospieszny T. Nieskalana sławą. Życie i dzieło Marii Skłodowskiej-Curie. Novae Res, Gdynia 2015.

3. Brandt S. The harvest of a century. Discoveries of modern physics in 100 episodes. Oxford University Press, Oxford 2009.

4. Pospieszny T. Radowa księżniczka. Historia Ireny Joliot-Curie. Novae Res, Gdynia 2017.

5. Röntgen WC. Ueber eine neue Art von Strahlen, Vorläufige Mitteilung. In: Aus den Sitzungsberichten der Würzburger Physik.-medic. Gesellschaft Würzburg, 1895; 137-147.

6. Pospieszny T. Pasja i geniusz, kobiety, które zasłużyły na Nagrodę Nobla. Wydawnictwo Po Godzinach, Warszawa 2019.

7. Skłodowska-Curie M. Badanie ciał radioaktywnych. Reprint wydania z 1904 roku. Komitet Historii Nauki i Techniki, Wydział I Nauk Społecznych PAN, Warszawa 1992.

8. Curie E. Madame Curie. Reprint z 1938 roku. Ishi Press International, New York 2017; 160-161, 164.

9. Malley MC. Radioactivity. A history of a mysterious science. Oxford University Press, Oxford 2011.

10. Curie Mme S. Rayons émis par les composés de l'uranium et du thorium. Comptes Rendus Acad Sci 1898; 126: 1101-1103.

11. Curie $P$, Curie Mme $S$. Sur une substance nouvelle radioactive, contenue dans la pechblende. Comptes Rendus Acad Sci 1898; 127: 175-178.

12. Curie P, Curie Mme P, Bemont G. Sur une nouvelle substance fortement radioactive, contenue dans la pechblende. Comptes Rendus Acad Sci 1898; 127: 1215-1218.

13. Skłodowska-Curie M. Autobiografia i wspomnienia o Piotrze Curie. Dom Wydawniczo-Promocyjny GAL, Warsaw 2004; 49, 178-179.

14. Mould RF. Radium history mosaic. Nowotwory Journal of Oncology, Warsaw 2007; 53-68.

15. Blanc K. Małżonkowie Curie i nagrody Nobla. Nauka i Szkolnictwo Wyższe 2011; 2: 10-14.

16. Blanc K. Maria Curie i Nagroda Nobla. Nauka Polska 1998; 7: 39-50.

17. Blanc K. Maria Curie et le Nobel. Uppsala Studies in History of Science, 26, Szwecja 1999. 